\title{
Las reediciones del Auto de fe de Logroño en vida de Moratín
}

RENE ANDIOC

Universidad de Perpignan

Para Anita, notoria hechicera

\begin{abstract}
A principios de 1611 , concretamente los días 6 y 7 de «Henero de mil y seyscientos y diez años, digo onze», según reza con escrupulosidad el texto original, consiguió el impresor de Logroño Juan de Mongastón la necesaria aprobación y licencia para estampar la Relación de una de las «cosas más notables q. se an visto en muchos Años", es decir, el auto de fe celebrado en la misma ciudad en noviembre de 1610 , reláción muy conocida ${ }^{1}$, a pesar de ser una de tantas que fueron apareciendo a lo largo del XVII, por haberla rescatado del olvido en el segundo centenario de su publicación don Leandro Fernández de Moratín, bajo el gobierno del Intruso. El 21 de octubre de 1811, la Gazeta de Madrid ponía en efecto en conocimiento de sus lectores que en el
\end{abstract}

1 Relación de las personas que salieron al Auto de la Fee, que los Señores Doctor Alonso Bezerra Holguín, del Ámbito de Alcántara, Licenciado Juan de Valle Alvarado, Licenciado Alonso de Salazar Frias, Inquisidores Apostólicos del Reyno de Navarra y su Distrito, celebraron en la Ciudad de Logroño en siete y en ocho días del mes de Noviēbre de 1610 Años. Y de las cosas y delitos por que fueron castigados.

Agradezco a mi amigo C. Morange la fotocopia de uno de los dos ejemplares de este documento conservados en la Biblioteca Nacional de Madrid. 
despacho de la Imprenta Real se vendía a cuatro reales una obra intitulada Auto de fe celebrado en la ciudad de Logroño en los días 7 y 8 de noviembre ${ }^{2}$ del año de 1610, siendo Inquisidor General el Cardenal Arzobispo de Toledo don Bernardo de Sandobal y Roxas. Segunda edición, ilustrada con notas por el bachiller Ginés de Posadilla, natural de Yébenes ${ }^{3}$. Ya he mostrado en otro lugar que, si bien usó de un seudónimo, añadiendo incluso pormenores biográficos imaginarios (por lo que pudiese tronar, según dijera su Doña Irene...), don Leandro facilitó también en sus notas unos poquísimos datos bibliográficos suficientes como para permitir la identificación del verdadero autor de ellas por cualquier aficionado a sus obras teatrales ${ }^{4}$. El caso es que en su Histoire Critique de l'Inquisition d'Espagne, editada en 1817-1818, Llorente sabe ya que la relación del auto «a été publiée à Madrid en 1810 (sic), avec des remarques très plaisantes, par le Molière de l'Espagne» ${ }^{5}$, apelativo que le diera a Moratín en 1794 su amigo Pedro Estala ${ }^{6}$.

Abolida la Inquisición por Napoleón el 4 de diciembre de 1808 y suprimidas todas las órdenes religiosas desde agosto del año siguiente, se encontraba el dramaturgo en condiciones relativamente favorables para contribuir a dejar constancia documental, según escribe en el prólogo ${ }^{7}$ de la «calamidad» que fue a su juicio el difunto tribunal, entonces más que nunca blanco de las sátiras de los regalistas y católicos ilustrados, símbolo de oscurantismo y opresión para muchos españoles de ambos bandos, y asimilado por la propaganda del ocupante a la España «retróga-

2

3 Las iniciales mayúsculas son mías, pues todo el título está
menos el nombre del autor, impreso en versalitas cursivas.

4 «Sobre Moratín y Goya», Hispanic Review, Spring 1982, pp. 119-132.

$5 \quad$ T. 2, P., 1818, p. 61 .

6 El Pluto, M., Sancha, MDCCXCIV, p. 43.

7 No está en la B.A.E. Lo transcribo al final de este artículo. 
da", es decir, sublevada contra el invasor. Por otra parte, como escritor que era, don Leandro no podía por menos de celebrar una medida que acababa con un enfadoso control del pensamiento ejercido por lo común en su tiempo, según informaba ya Jovellanos en 1798, por unos calificadores carentes de la debida competencia ${ }^{8}$; «Vergüenza es referirlo -escribía Inarco-; pero también no es pequeño desahogo el poderlo ya referir» ${ }^{9}$. Estas últimas palabras se extractan de un prólogo que, sintomáticamente, contiene un violento ataque al Santo Oficio y se redactó en 1811 para encabezar una fracasada edición del Fray Gerundio, concediéndose licencia de impresión el 4 de abril de aquel año. Además, a los pocos días de anunciarse en la Gazeta la publicación del Auto de Fe de Logroño, Juan Antonio Llorente leía en la Academia de la Historia su Memoria histórica sobre quál ha sido la opinión nacional de España acerca del tribunal de la Inquisición ${ }^{10}$, dándola a la imprenta el año siguiente, en que también se publicaron sus Anales de la Inquisición de España; como se ve, no se trata, en lo que a Moratín se refiere, de un mero caso aislado, ni en su propia obra, ni en la producción de aquellos años, sino de un fenómeno más amplio generado por unas circunstancias muy particulares. Es más; desde Cádiz llegaban noticias a la Villa y Corte, y la Gazeta de Madrid les dedicaba una pequeña sección en la que se publicaban, anotándolos a

9 Obras póstumas, III, p. 207. También la emprende don Leandro con los «nietos de los Infantes de la Cerda [...] descendientes de Alfonso el Sabio» que, según nota 5, se dedican al «vergonzoso empleo» hereditario de alguaciles mayores del Santo Oficio: se trata de los duques de Medinaceli (Bourgoing, Tableau de l'Espagne moderne, París, Levrault, 1803, I, p. 384); el primogénito, marqués de Cogolludo, iba al frente de la comitiva en el auto de 1784 en que se sentenció a un mendigo fabricante de filtros amorosos, tal vez representado en el Capricho 23 de Goya. En la víspera de la Guerra de la Independencia, se menciona en las Guías del estado eclesiástico como alguacil mayor y teniente, respectivamente, a Medinaceli y Cogolludo.

Dos años antes de la reedición del $A$ Ato por Moratín, un decreto imperial declaraba al duque de Medinaceli y a otros grandes «enemigos de Francia y España y traidores a ambas coronas» (Artola, Los afrancesados, Madrid, Sociedad Estudios y Publicaciones, 1953, pp. 114$115)$.

10 Reeditada hace poco, con un estudio iluminativo, por G. Dufour, París, P.U.F., 1977. Doy las gracias a mi estimado colega por haberme ayudado a aclarar algunas dudas. 
veces con ironía, extractos de periódicos y títulos de folletos por los que pudo enterarse don Leandro el 18 de noviembre de 1811 -después de editado el Auto, por supuesto-de que el Redactor General del 13 de octubre anunciaba uno de los muchos «papeles» entonces impresos en contra del Santo Oficio, intitulado Incompatibilidad de la libertad española con el establecimiento de la Inquisición, por «Ingenuo Tostado».

Del texto aureosecular conozco dos ejemplares, ya citados por Julio Caro Baroja en Las brujas y su mundo, que se custodian en la Biblioteca Nacional de Madrid; uno de ellos suelto y otro incompleto, incluido en una colección manuscrita de Cédulas reales a favor del Santo Oficio y, por lo mismo, conservado en la sección de Manuscritos de dicho establecimiento ${ }^{11}$. Es posible que Moratín leyera uno de los dos en la Biblioteca Real, después Nacional, de la que le habían de nombrar bibliotecario mayor en noviembre de 1811 , unas pocas semanas después de su edición anotada del $\mathrm{Auto}$ de $\mathrm{Fe}$. Como quiera que fuese, la reedición del texto del Siglo de Oro por Moratín es, según queda dicho, de 1811 y no de 1812 como se ha venido repitiendo, con alguna que otra excepción, hasta una fecha bastante próxima ${ }^{12}$, y tal equivocación se deriva indudablemente del escasísimo número de ejemplares que de aquella obra han sobrevivido: el único que yo conocí durante años era propiedad del difunto marqués de Valdeterrazo, y se menciona en el catálogo de la exposición en torno a Moratín en el segundo centenario de su nacimiento, que se celebró en la Biblioteca Nacional de 1960 a $1961^{13}$; Francisco Aguilar Piñal, en su preciosa bibliografía del autor, no lo señala, pero en cambio dio con otro en la Biblioteca del Hebrew Union

11 Signaturas respectivas: $\mathrm{V} / \mathrm{C}^{\mathrm{a}} 248, \mathrm{n} .{ }^{\circ} 71, \mathrm{y} \mathrm{ms} .718$, fols. 271 y ss. Véase también, de Caro Baroja, Brujería vasca, San Sebastián, Txertoa, 1982, pp. 73 y ss.

12 He mostrado en un trabajo anterior (véase n. 4) que las notas moratinianas no son de 1797 , como se ha escrito equivocadamente con el fin de justificar una supuesta influencia de ellas y del texto del Auto sobre los Caprichos brujeriles de Goya; son anteriores en algunos meses a la fecha en que se publicaron por vez primera en Madrid.

13 Valencia, Amparo Soler imp., 1961, pp. 41-42, n. ${ }^{\circ} 242$. 
College de Cincinnati, Ohio, que es el que utilizo en el presente trabajo ${ }^{14}$. Conviene recordar a este respecto que don Marcelino conocía, hace ya más de un siglo, el año exacto de la llamada por Moratín segunda edición, esto es la del seudo bachiller Ginés de Posadilla, exornada, según frase del erudito santanderino, «con notas sazonadísimas aunque un tanto volterianas $\rangle^{15}$; pero unos treinta y tantos años más tarde, Agustín González de Amezúa, en su edición de El casamiento engañoso y el Coloquio de los Perros ${ }^{16}$, advierte al lector que «la Relación del auto de fe de Logroño [la] reimprimió Moratín bajo pseudónimo en 1812», es decir que, como muchos, se equivoca doblemente, pues no sólo desconoce la edición del año anterior sino que además atribuye a don Leandro una iniciativa que no tomó en 1812 porque no le era posible tomarla, como más adelante se verá. Por lo mismo, el juicio poco favorable que formula acerca de la que considera primera reedición de la Relación no puede ya sostenerse; escribe en efecto Amezúa que «no merece crédito. Obrando de mala fe, que muy capaz era él de éstas cosas, no la reprodujo fielmente, sino con importantes variantes y supresiones. Acreedora es, por tanto, a que algún aficionado a estos estudios la saque nuevamente a luz en toda su integridad». Me parece lícito pensar que entra en esta formulación parte del concepto poco grato que tenía formado de los llamados «afrancesados» en general la intelectualidad de aquellos años (y que aún perdura entre sus cada vez más escasos seguidores; en efecto, que el texto de la Relación tal como apareció en 1812 esté menos pulcramente editado que el del año anterior queda fuera de duda; contiene unas erratas - contadas por cierto- que denotan la prisa y el consiguiente poco cuidado con que se imprimió: «respuesta» por "reqüesta»; faltan un par de conjunciones que en ningún modo afectan al sentido de la fra-

14

Cuadernos bibliográficos, n $.^{\circ} 40,1980$, p. 35 . La entidad norteamericana tuvo a bien facilitarme fotocopia del documento, y R.P. Sebold, como buen amigo, medió en la tramitación del asunto.

15 Biblioteca de traductores españoles, Madrid, C.S.I.C., MCMLIII, vol. III, p. 391 (la fecha de redacción es 1874-1878, según la introducción al vol. I).

16 Madrid, Bailly-Baillière, 1912, p. 718. 
se; un verbo en plural en vez de singular, también sin consecuencias pues el sujeto puede ser único o múltiple en aquel contexto particular; falta, sí, un complemento de dos que se pueden leer en el original áureo, pues el impresor de 1812, partiendo del texto publicado el año anterior por Moratín, se saltó un renglón de éste. Pero donde hay muchas «variantes» y «supresiones» es en las notas (por motivos que también se examinarán en su lugar), no en el texto. Y menos aún las hay en el de la pulcra reedición de 1811 , si bien van en cifras las fechas y ya no en letras, se unifican o modernizan unos pocos apellidos o topónimos (de «Cigarramurdi» y «Zugarramurdi» se conserva la segunda forma; «Yriart» se convierte en «Iriarte»), y se olvida el impresor de puntualizar que el brazo del niño con que se alumbran los brujos es el izquierdo. Incluso, a pesar de atenerse a las normas ortográficas vigentes o más corrientes en su época, Moratín respeta las formas arcaicas («mesma», «dalde», etc.). No se puede por tanto hablar de "variantes importantes» que desacrediten la edición ${ }^{17}$.

En cambio sí resolvió suprimir deliberadamente y, al parecer, no sin vacilaciones, un pasaje y dos frasecitas que paradójicamente se pudieron estampar en 1611 y hubiera tachado no obstante, sin la más mínima duda, un censor de 1811; y por haberlo sido Moratín poco antes de estallar la guerra, cuando su amigo Melón regentaba el juzgado de Imprentas, encargándole el examen de varias obras, sabía que no se podían rebasar ciertos límites, sobre todo en lo escabroso; porque de esto se trata, y no de otra cosa. Ocioso es decir que esas supresiones se reiteraron en las reediciones sucesivas, hasta la última, que es la de 1846 realizada para la Biblioteca de Autores Españoles de Rivadeneira. El mismo autor, mejor dicho, los mismos autores de la Relación áurea, al aludir a «otras [maldades] muy abominables que se dexan de referir ${ }^{18}$, también tenían perfecta conciencia de rozarse

17 Se modifica el orden de sucesión de la aprobación, la licencia y la advertencia de Mongastón, y se omite además, por inútil, en la p. 24, el título que en la ed. de 1611 encabezaba el relato de las actividades de los brujos.

18 B.A.E., II, p. 625 a. 
con lo nefando, en el sentido etimológico de la voz, por lo que Moratín no hizo más que conformarse anticipadamente al dictamen de la censura oficial; pero fue indudablemente para él un cargo de conciencia el tener que censurar un texto que demostraba «tan torpe y hedionda estupidez por parte de sus autores»; prueba de ello, la larga nota en que expuso ese debate interior en forma de diálogo entre varias personas, entre ellas el «editor», esto es, él mismo, poco antes de empezar el relato de la misa negra y las travesuras colectivas en que desemboca; en ella se enfrentan tres actitudes: uno es de parecer que no se imprima; otro que sí; $y$ el tercero elige un término medio que consiste en publicar el texto antiguo, «pero al llegar a eso de la misa, y lo que se dice más allá, salto, y puntos suspensivos; y ate vmd. el hilo en donde mejor le parezca»; después de un intercambio de argumentos, dos votan la edición íntegra, el otro se abstiene, o más bien opina que debe obrar el editor según su propio criterio; éste se adhiere al último parecer, con la aprobación de uno de los dos primeros, el cual evidencia así, al finalizar la nota, la propia incertidumbre y la de todos ante una solución de cualquier forma no satisfactoria ${ }^{19}$. Y como sabe ya el lector, Moratín imprimió el relato de la misa negra, pero en el de la «gresca obscena» no pudo por menos de practicar unas cuantas podas, sin las cuales no se hubiera publicado el texto del auto, pues lo que importaba era publicarlo; al fin y al cabo, se le planteó a don Leandro el mismo problema que han tenido que afrontar los escritores e investigadores en una época muchísimo más cercana a la nuestra... Y tanto menos se le puede afear esa conducta cuanto que demostró el máximo de honradez intelectual entonces tolerable cuidando de señalar con puntos suspensivos los pasajes suprimidos ${ }^{20}$, precaución ésta que no se hubiera tomado la censura oficial, ni entonces, ni más tarde. En desagravio, pues, de Juan de Mongastón y de los inquisidores del XVII, y también para conferirle a la edición moratiniana el «entero crédito» que le niega equivocada- 
mente González de Amezúa, transcribo a continuación y en cursiva aquellas frases pecaminosas ${ }^{21}$ de que se quedaron en ayunas los súbditos efímeros de José Bonaparte, y, con ellos, los lectores de las ediciones sucesivas basadas en la de Moratín:

[...] la llevavan a la parte donde estava el Demonio, que luego con su mano yzquierda (a la vista de todos) la tendía en el suelo boca abaxo, o la arrimava contra un Arbol, y allí la conocía sométicamente, estándole haciendo el son el dicho su marido Joanes de Sansín, y estando en el dicho acto, ella dava un chillido muy rezio q. le oyan todos, y preguntadas $q$. formasen el chillido en la forma que lo hazían, es como quando brama un toro. Y luego que acabavan los actos desonestos, haziéndole el son, yendo ella muy ufana y contenta, la bolvían a llevar al puesto donde la avían sacado; y en la dicha forma la dicha Reyna yva señalando todas las que avian de yr a se juntar con el Demonio; y con la dicha música y solemnidad las yvan llevando, y bolviendo a sus lugares dando todas siempre el dicho chillido quando acabavan los actos desonestos. Y la dicha maria Yriart, hija de la Reyna, declara que quando su madre la mandó que fuese la primera vez para el dicho effecto, el Demonio la trató carnalmente por ambas partes, y la desfloró y padeció mucho dolor, y bolvió a su casa la camissa muy ensangrentada, de que se quexó a su madre, y ella le respondió que no importaba nada, que también avía hecho con ella otro tanto. Y Miguel de Goyburu refiere en la forma que se desatacava para el dicho efecto, y otras muchas cossas torpissimas que le pasaron con el Demonio, que por serlo tanto se dixo en la sentencia que no se referían. Y Martín de Vizcar, Bruxo reconciliado (que en el Aquelarre tenía officio de Alcalde, para regir y governar los niños), refiere que la primera vez que el Demonio lo conoció sométicamente, padeció gran dolor y llevó a su casa mucha sangre; y para dar satisfación a su muger (que le preguntó qué sangre era aquélla) fingió que con un ramo de una mata se avía herido en una pierna. Y luego que el Demonio acaba [...]

[...] y de noche se les aparece el Demonio en espantosa figura y los conoce carnalmente, y a las mugeres por ambas partes y muy de ordinario se les va a las camas [...] señalar los pasajes omitidos por don Leandro en su edición de 1811 .

Me atengo a la ortografía del texto original, pero con excepción de la vocal $v$ («vnos»), de la consonante $u$ («lleuaua»), y de la tilde que convierto en $n$ («boluiã »). 
Por lo que hace a las notas con que don Leandro adornó su edición del texto del siglo XVII, «volterianas hasta los tuétanos - según Menéndez y Pelayo ${ }^{22}$ - e hijas legítimas del Diccionario filosófico", se ha escrito que no se había lucido en ellas y que al tratar de brujería, «entre el sentido histórico del patriarca de Ferney y los resabios anticlericales de nuestro gran hombre de teatro» había mucha distancia ${ }^{23}$. «No resistió la tentación de usar hechos tan extraordinarios para pavonear su dominio del estilo satírico», encarece R. Cueto Ruiz, y en la 52, relativa a los «hechizos» de Carlos II, «no se conformó con la información disponible», llegando a convertir los datos históricos en «farsa vulgar y corriente» ${ }^{24}$.

No sé en qué medida se pueden calificar de "volterianas» las notas de Moratín; basta con que sean moratinianas, que ya es mucho. Lo cierto es que Inarco cita varias veces al escritor francés, y que en cambio, tres años escasos antes, no se hubiera atrevido a tanto, a pesar de haber leído, según escribe en 1795, «todo el V.» ${ }^{25}$. Esta prudente abreviatura, que lo explica todo, supone una constante preocupación por la censura, que había de desembocar fatalmente en el desahogo que se tomó el autor a raíz del cambio de régimen, de manera que el anticlericalismo de las notas resulta más lógico en ellas que la serenidad del historiador, ya que, además, corresponde a la elección, tampoco casual, del texto del Siglo de Oro. Ello equivale a decir que no se deben juzgar las notas moratinianas a partir de criterios que no les corresponden, y que deben acompañarse por otra parte de cierto distanciamiento generador de objetividad. De todo ello tiene por cierto perfecta conciencia el propio don Leandro, pues el «prólogo del editor» evidencia que no pretendió más que «producir documen-

22 Cit. por Caro Baroja, Las brujas..., p. 219. Compárese ese juicio, procedente de la Hist. de los Heterodoxos, con el citado más arriba, del mismo don Marcelino.

23 Id., ibid., p. 219.

24 Los hechizos de Carlos II, Madrid, La Ballesta, 1966, p. 20.

25 Epistolario, Madrid, Castalia, 1973, carta 56. 
tos para que otras plumas, sin exageración, sin parcialidad, sin encono, describan el origen, los progresos y el suspirado término de nuestra calamidad» ${ }^{26}$, esto es, «el atraso» de España, cotejada con las naciones de Europa a principios del XIX. Por otra parte, no dista mucho de acertar Cueto Ruiz, si bien involuntariamente, al calificar de farsa la versión moratiniana del proceso de Froylán Díaz ${ }^{27}$; y es que el autor no debió de conceder demasiada importancia a sus comentarios, redactando tan sólo, dice, «algunas notas», en las que «de propósito» desistió de «tomar en consideración lo que hay en él [el auto de Logroño] de repugnante y horrible», prefiriendo "aprovechar las ocasiones que ofrecen a la pluma las ridiculeces de que abunda tal escrito». «Si por este medio - concluye - ha conseguido hacer su lectura menos desagradable, quedará suficientemente premiado el corto mérito que haya podido contraer en solicitar su publicación».

Pero a pesar de su enfoque esencialmente satírico, conviene observar que Moratín no se contentó con hacer alarde de su «facilidad difícil», o, digamos, de su mero talento, sino que también se tomó la molestia de informarse previamente leyendo el discurso manuscrito redactado en abril de 1611 por Pedro de Valencia a petición del Inquisidor General «acerca de los cuentos de las brujas» castigadas en Logroño. Dicho manuscrito, concretamente el Discurso primero, debió de leerlo Moratín, como la relación del auto, en la Biblioteca Real, y permaneció inédito hasta principios de nuestra centuria ${ }^{28}$. La lectura del texto de Pedro de Valencia por don Leandro explica la mención del Inquisidor General, Bernardo de Sandoval y Rojas, a quien va dirigido, en el título de la edición de $1811^{29}$, ya que de él no se trata en la anterior

27 Lo que importa es que don Leandro lo leyera. Por otra parte, en tres de los cuatro pasajes de la nota 52 (cito por la ed. de la B.A.E.) incriminados por Cueto, la «invención» de Moratín se reduce a una mera broma sin trascendencia. Por último, tampoco están libres de erratas las citas del propio Cueto... 
de Mongastón; por otra parte, interesa advertir que el juicio de Moratín acerca de la histeria brujeril corresponde al de Valencia y de la minoría de escépticos que, en el segundo decenio del seiscientos, se negaban a castigar «delitos que es imposible cometer». Recuérdese de pasada que a los dos años de publicada la Relación por Inarco, se empeñaría Fray Francisco de Alvarado en defender en las Cortes la creencia en las brujas... ${ }^{30}$.

En cambio, el autor de El si de las niñas no tuvo noticia de la actividad incansable de Alonso de Salazar y Frías, el más reciente de los tres inquisidores logroñeses, nombrado por su protector Sandoval en 1609 durante la instrucción del proceso ${ }^{31}$, de manera que la última nota de la edición de 1811 le atribuye sarcásticamente la misma «satisfacción» y «contoneo» que a sus colegas más antiguos Valle Alvarado y Becerra y Holguín. Efectivamente, según escribe J. Caro Baroja, los documentos que prueban la discrepancia de Salazar «y su agudo sentido crítico no fueron conocidos hasta mucho después de que su fama y memoria fuese objeto de una parte de las burlas aludidas», es decir, hasta la Historia de la Inquisición española de Lea y los trabajos, más cercanos a nosotros, del mismo Caro Baroja, Kamen, Bennassar, Henningsen y otros. El último describe con todos sus pormenores la lucha, si bien minoritaria y larga, no del todo aislada, que entabló aquel «abogado de las brujas» contra sus dos colegas, y el consiguiente viraje de la Suprema, que acabó dictando en 1614 nuevas intrucciones para los casos de brujería, lo que no impidió por cierto en los años sucesivos que las autoridades seglares, presionadas por el vecindario, siguiesen quemando a los adictos a esa herejía, ni que muchos inquisidores continuasen tan aficionados a hogueras como antes ${ }^{33}$.

\footnotetext{
30 Gustav Henningsen, El abogado de las brujas, Madrid, Alianza Editorial, 1983, p. 343.

31 Id., ibid., cap. X y ss.

32 Las brujas..., pp. 220-221.

33 Henningsen, p. 342.
} 
Pero el auto de Logroño, según advierte Henningsen fundándose en la documentación reunida por Salazar, constituyó una ruptura en la tradición inquisitorial de no quemar brujos; habla incluso el historiador danés del «increíble escepticismo» manifestado en casos semejantes por la Suprema durante el siglo XVI en comparación con el modo de proceder de otros jueces de Europa ${ }^{34}$. El caso es que los autores ${ }^{35}$ de la Relación impresa en 1611 sólo conceden unas pocas líneas a los acusados de herejía ordinaria (luteranos, apóstatas, judaizantes, etc.), dedicando la mayor parte del folleto a la «Relación de las cossas / y maldades que se cometen en la seta de los Bruxos / según se relataron en sus sentencias y / confesiones» ${ }^{36}$, lo cual confirma el asombro de la concurrencia al oír esas "cossas tan horrendas y espantosas quales nunca se han visto» ${ }^{37}$, y por ende el carácter marcadamente excepcional de aquel «auto público general», celebrado once años después del inmediatamente anterior y al que se mencionó significativamente largo tiempo en los círculos inquisitoriales como «auto de las brujas» ${ }^{38}$. De manera que si en algo pecó Moratín fue en generalizar implícitamente a partir del contenido del auto de Logroño. Pero en modo alguno se considera, al menos expresamente, «historiador erudito y filósofo» al reeditarlo ${ }^{39}$. Se

34 A la "prudencia» del procedimiento inquisitorial se refieren también Caro Baroja (o.c., p. 197), Bennassar (Inquisición española: poder político y control social, Barcelona, Crítica, 1981, passim).

35 Henningsen (p. 187) califica a Mongastón de «testigo ocular» e, implicitamente, de autor de la Relación. Los autores verdaderos, al menos si prestamos fe al mismo texto del Siglo de Oro, fueron «algunos curiosos» que iban sacando notas durante la celebración del auto y que encargaron a uno de ellos la redacción de una síntesis ([...] pondré también una breve relación de algunas de las cosas más notables que apuntamos [...]). Mongastón sólo dice que la relación «ha llegado a sus manos» (B.A.E., II, pp. $618 b$ y $617 a$ respectivamente).

36 Moratín (o su impresor) no transcribió este subtítulo, separando la referida «relación» del texto anterior.

37 P. $618 a$.

38 Henningsen, p. 176; cf.: «Este Auto de la Fe es de las cosas más notables que se han visto en muchos años...» (p. $617 \mathrm{~b}$ ).

39 Ed. de Madrid, 1811, p. 4 (véase apéndice).

Pero añade a renglón seguido: «¿Quién de nosotros había de escribir en tiempo de tinieblas y opresión?" (acerca de la Inquisición, se entiende). 
trata, sí, de un miembro de la intelectualidad ilustrada, buen conocedor -dentro de los límites impuestos por la época- de la historia de su país y de los problemas políticoculturales en los que, volens nolens, anduvo mezclado como escritor, como alto funcionario y también por estar vinculada su suerte a la de los poderosos durante el reinado de los Borbones y el de José Bonaparte. El plan de futuras investigaciones que propone don Leandro a los "más acreditados escritores" supone una previa y honda reflexión que le lleva a incluirse - ¿retóricamente?- en el número de los frustrados historiadores de la «Santa» ${ }^{40}$. ¿Quién sabe por lo tanto si no abrigaría algún día la intención de dedicarle un trabajo? Lo cierto es que debido a las circunstancias, a su dedicación casi exclusiva a otro tipo de actividad, a la falta de tiempo y serenidad, también a la edad, el autor de los Orígenes del teatro español no estaba en condiciones de emprender entonces una obra de esta clase, a diferencia de un Llorente que poseía desde tiempo atrás la experiencia y documentación imprescindibles. Moratín eligió pues un término medio, que fue publicar un documento histórico y, por medio de notas apropiadas, convertirlo en panfleto, para él más fácil de redactar por tener mayor afinidad con su genio satírico y con la «extraordinaria revolución» ${ }^{41}$ importada de tras el Pirineo.

El año siguiente de 1812, en Cádiz, entonces capital de la resistencia al invasor, la imprenta Tormentaria realizó, con escaso cuidado por cierto, al menos en lo estrictamente tipográfico, la reedición que, como queda dicho, hasta una fecha reciente se ha venido considerando como primera reimpresión del texto de Mongastón con las notas de Moratín ${ }^{42}$. La portada contiene ya una errata importante, pues al impresor gaditano, menos mirado que el madrileño, se le quedó en el tintero, y mejor dicho en la ca-

40 Véase nota anterior.

41 Prólogo para el Fray Gerundio, Obras Póstumas, III, p. 209.

42 A. Milhou ha tenido la amabilidad de mandarme fotocopia del impreso 1/3997 de la B.N. de Madrid. 
ja, la mención del número de la edición, de manera que el que no conozca la portada de 1811 no alcanza a qué se refiere el participio femenino «ilustrada con notas...» en un título que trata de un «Auto de Fe»; se pueden espigar varios descuidos más en las notas, como «entrando» por «encontrado»; «rodeo» por «regodeo»; «atenciones» por «anotaciones»; «viages» por «visages», etc.; el gaditano parece además reñido con los diminutivos («pantalón» en vez de "pantaloncito»; «sobrino» por «sobrinito»); dos referencias a la página 97 se han copiado mecánicamente de la edición anterior y, como es natural, no corresponden a la nueva foliación ${ }^{43}$. Del texto propiamente dicho ya se ha hablado; añádase que el nuevo editor se ahorra muchas iniciales, quizá no en todos los casos sin segunda intención («... la santa cruz verde, insignia de la inquisición...»; «... que es calificador del santo oficio...»).

Pero esta serie de imperfecciones y algunas más, que contrastan con la pulcritud de la impresión realizada antes por los tórculos josefinos, no se deben tanto a la desidia de la bien llamada «Tormentaria», según parece, como al apremio de las circunstancias, las cuales requerían, como vamos a ver, una pronta publicación del texto y notas por el «editor», más concretamente por el anónimo que, sin anuencia del ausente editor, o sea Moratín, deseaba intervenir lo antes posible en la encarnizada polémica iniciada meses atrás, en julio-agosto de 1811, es decir, tal vez antes de que don Leandro pensase realizar en Madrid su propia edición ${ }^{44}$. El contexto de la aparición del Auto de Fe en Cádiz es en efecto el de la lucha entre adversarios de la Inquisición y partidarios de su restablecimiento, y viene a constituir el texto del XVII con las notas moratinianas un folleto más entre los muchos que aparecen a favor o en contra de la incompatibilidad del Tri-

43 En cambio aparece ya generalizada la ortografia moderna «cu-», que sustituye a «qu-» («cualquiera», «cuanto», «cuadrilla», etc.), con una sola forma todavía híbrida debido a la conservación de la diéresis, en «cüestión».

44 Véase Ramón Solís, El Cádiz de las Cortes, Madrid, Instituto de Estudios Políticos, 1958, pp. 332 y ss. 
bunal con la Constitución promulgada el 19 de marzo de 1812 . Una nota final de la edición gaditana nos informa acerca de los móviles de sus realizadores y permite a la vez fecharla con alguna aproximación: en ella se denuncia a los «apologistas del tribunal de Inquisición», a los que "procediendo de mala fe desean el restablecimiento de este tribunal de horror», y por último a quienes "prestan sus nombres para restablecer tan criminal institución»; en esta última frase se alude indudablemente a la campaña organizada por los serviles para reunir firmas no sólo yendo de casa en casa, sino también solicitando a prelados y oficiales de alta graduación, cuyas identidades fueron conocidas en junio-julio de $1812^{45}$. El 22 de abril ${ }^{46}$, la comisión nombrada para informar sobre la oportunidad de reponer el Santo Oficio hizo público un voto positivo amañado en condiciones al parecer no muy regulares (¿serán los que procedieron «de mala fe», valiéndose de «medios capciosos y subversivos»?), aunque se consiguió, con no menor habilidad maniobrera, hacer pasar el expediente a la Comisión de Constitución con el encargo de informar sobre la incompatibilidad de la «Santa» con dicha constitución ${ }^{47}$, de lo cual resultó un aplazamiento de la discusión por los diputados hasta el 8 de diciembre, en que se propuso la abolición; el 4 de junio se había votado ya en comisión el principio de la incompatibilidad, que se había de confirmar en el artículo segundo del decreto de abolición de 22 de enero de 1813, publicado el 22 de febrero. Al principio de incompatibilidad se refiere expresamente la frase de la advertencia final en que se afirma que «este instrumento de la tiranía [...] no existe, o no puede existir la Constitución que hemos jurado». El que esperen los gaditanos «anciosos» [sic] el día memorable en que el Soberano Congreso Nacional declare que no existe aquel monumento de degradación del género humano"

45 Solís, pp. 342-343. Resulta bastante difícil captar la cronología de los acontecimientos en este libro.

46 F. Martí Gilabert, La abolición de la Inquisición, Pamplona, EUNSA, 1985, p. 105. Modesto Lafuente (Historia General de España, vol. 13, p. 117) habla del 22 de mayo.

47 Actas de las Cortes de Cádiz, Madrid, Taurus, vol. II, 1964, p. 1.030. 
permite inferir que la publicación del Auto de Fe debe de situarse a finales del año de 1812; lo confirma una frase de la intervención del diputado a Cortes Ruiz de Padrón en la sesión del 18 de enero de 1813: «El de Logroño del año de 1610 se ha reimpreso en estos días... ${ }^{48}$.

No debe extrañar la publicación en el Cádiz de las Cortes de un texto editado con poca anterioridad en Madrid por un funcionario del Intruso, pues liberales y afrancesados, como es notorio, no carecían de afinidades ideológicas, particularmente en lo que a la Inquisición se refiere, de manera que la utilización de un folleto del bando de enfrente por un «insurgente» distaba mucho de constituir un caso aislado; según se ha demostrado hace poco, se aprovechó en efecto por la comisión de Constitución el texto de la Memoria histórica sobre quál ha sido la opinión nacional de España acerca del tribunal de la Inquisición, que Llorente leyó en la Academia de la Historia el 15 de noviembre de $1811^{49}$, y por otra parte, ya hemos visto que se publicaban en la Gazeta de Madrid noticias procedentes de Cádiz ${ }^{50}$. Canarias y miembro de la comisión, no sólo estaba al corriente de la publicación del Auto de Logroño en 1812, sino que - al igual que sus compañeros (y sus adversarios) con la Memoria... de Llorente- supo aprovechar por su parte en su discurso el texto de la relación e incluso el prólogo, y más aún, la advertencia final añadida por el editor gaditano. Además de las coincidencias argumentales entonces corrientes (oscurantismo, usurpación de la autoridad episcopal, autoridad ilimitada), se advierten ecos textuales procedentes del prólogo moratiniano: «ha creído los mayores absurdos y castigados delitos que no es posible cometer» (Actas..., p. 1.156; escribe Moratín: «propagaba errores absurdos [...] castigaba delitos que es imposible cometer»); «recordarnos lo que hemos sido y advertimos lo que debemos ser en adelante» (p. 1.186; «se ignora mucho lo que fuimos, lo que somos ahora y lo que pudiéramos ser»). En la «fastidiosa difusión» de la intervención del diputado destacan dos temas utilizados en la breve conclusión de la ed. de Cádiz que no aparecen en el prólogo de don Leandro: el de la contradicción de los métodos inquisitoriales con la doctrina evangélica y, naturalemnte, el de la incompatibilidad de la Santa con la constitución.

La terminología of rece también indudables semejanzas, habida cuenta de la enorme disparidad cuantitativa de ambos documentos: 


\section{Dada la situación de beligerancia y la propaganda que afeaba}

la conducta de los afrancesados, secuaces del «Anticristo», no convenía mencionar en Cádiz los nombres de los «traidores»e «impíos» cuyos argumentos se aprovechaban para arremeter contra la «Santa» o lo que de ella quedaba, aunque tampoco sería inverosímil que el editor gaditano no tuviera ni idea de quién se parapetaba tras el seudónimo de Ginés de Posadilla.

Para precaverse contra la acusación obligada de impiedad o herejía esgrimida por los ultramontanos ${ }^{51}$, el gaditano dedica al

¿Y se ha podido llamar a este tribunal el Santo Oficio?

el tribunal llamado Santo Oficio

(p. 1185)

el tribunal llamado Santo Oficio

la respetable decisión de las Cortes que espera con ansia la nación entera

esperamos anciosos el día memorable en que el Soberano Congreso Nacional declare...

Acaso unos hablarán por ignorancia o estupidez, ... aquéllos por un celo indiscreto

Los que por su ignorancia, su preocupación y su zelo indiscreto...

El pueblo español ha jurado solemnemente su Constitución...; está pronto y dispuesto a defender y sellar con su sangre...

la Constitución que hemos jurado y que debemos sostener hasta derramar la última gota de nuestra sangre...

Demos - con precaución, un paso adelante: sabido es que después de votarse el 4 de junio de aquel año por la comisión de Constitución el principio de la incompatibilidad del Santo Oficio con la constitución española (Dufour, o. c., p. 27), se acordó, ante la discrepancia de dos de sus miembros, reunir todos los documentos necesarios para un debate sobre el particular, a los que convenía añadir las obras de todos «los escritores nacionales que, por incidencia o de propósito, han hablado de la Inquisición». Además, la advertencia de 1812 se refiere a «la Constitución que hemos jurado y que debemos sostener...», es decir, que su autor se expresa como diputado y no como un simple particular. Se podrá objetar que en el discurso de Ruiz de Padrón se escribe (p. 1.164) que «el pueblo español no ha jurado ni jurará jamás sostener la Inquisición; antes al contrario en el mismo acto de jurar la Constitución ha jurado virtualmente la abolición...»; pero en este caso, el orador habla como representante y en nombre de ese «pueblo» (el ejemplo cuarto es iluminativo a este respecto). En la advertencia final de la ed. del $A$ Ato se concibe en cambio difícilmente que un gaditano cualquiera pueda hablar en nombre de una determinada comunidad; a quien se refiere el sujeto plural es, pues, lógicamente, a los diputados, por expresarse, creo yo, uno de ellos. ¿No serán una misma persona Ruiz de Padrón y el editor gaditano? O, al menos, ¿no fue el diputado canario el que redactó o ayudó a redactar la advertencia final de la ed. de 1812 ? Se evoca también en su discurso la relación del auto de 1680 por José del Olmo, que se había de reeditar en 1820 como la del auto de Logroño.

51 "Que nos vengan ahora con la rancia y hedionda cantilena de que los que impugnan la Inquisición hasta exigir su total abolición son profanos, impíos, herejes, ateos, judíos, francmasones, jansenistas...» (Ruiz de Padrón, en Actas..., p. 1.189). 
menos la quinta parte de su advertencia final ${ }^{52}$ a justificar su empresa por medio de la no menos corriente cantinela de «los sacrosantos principios de una religión» con la que se hallan en «absoluta contradicción» los que sirven de fundamento a la institución inquisitorial, y en nombre de las «santas máximas del evangelio» por las que Jesucristo, lejos de persuadir a los hombres «con el cuchillo, la hoguera y la infamia [...] se inmoló en el ara de la cruz para redimir al género humano, cuyo exemplo fuera mejor que hubiesen imitado los inquisidores» ${ }^{53}$. La cautela con que maneja tan vidrioso asunto y la necesidad de acomodarse al contexto gaditano dan pie, por otra parte, a varias supresiones o alteraciones en las notas, pasando las sesenta de la edición moratiniana a cincuenta y cinco. En el prólogo, que sigue siendo el de don Leandro, desaparece ya la mención de la «Silla Romana», por lo que se silencia la procedencia de «la protección y el favor» de que gozó la Inquisición, y resulta además incomprensible el final de la frase. Queda también suprimida la breve nota 7 correspondiente a los dos embusteros que «fingiendo ser Ministros del Santo Oficio habían cometido grandes maldades» («Procurarían imitar bien lo que fingieron») ${ }^{54}$, tal vez por insinuar sarcásticamente que sus desmanes eran consecuencia lógica de una perfecta asimilación. En la 16 se censuró el final de la frase en que se evoca jocosamente a un ánima en pena «pidiendo pesetas a los circunstantes para que le digan misas», y también en este caso resulta coja la frase por haberse truncado sin consideración a la sintaxis, debido sin duda, según dejamos apuntado más arriba, al deseo de contestar sin demora a los partidarios de la «Santa». Por otra parte, el hacer burla de la excesiva devoción popular a María relacionándola con la «ignorancia» y calificando incluso de «numen» a la Virgen, aunque todo ello sea volver por los fueros de la trastrocada jerarquía celestial, era del todo improcedente en aquellas circunstancias en que, mientras los serviles habían elegi-

52 Véase apéndice.

53 No inmolándose, por supuesto, sino ayudando a redimir al género humano...

54 La numeración que utilizo es la de B.A.E., para que resulte más fácil la tarea para el lector. 
do a Santiago el de Clavijo como patrono de España y los liberales sentían predilección por Santa Teresa ${ }^{55}$, la Virgen en sus distintas advocaciones acaudillaba a los defensores de la patria: la de Atocha ${ }^{56}$, la «Verge pura» de Montserrat ${ }^{57}$, la del Pilar que, como es notorio, no quería ser francesa, la de los Dolores a quien la Madre María Rosa de Jesús proponía nombrar en Cádiz generalísimo de las tropas ${ }^{58}$, la de Covadonga ${ }^{59}$, etc. Y ésa fue la causa de la desaparición de la nota 18 . Una chanza análoga en la 20 a propósito de la eficacia del nombre de Jesús para conjurar a los demonios tampoco pasó a la edición de Cádiz, pero el resto de la nota se desechó por razones que examinaremos más adelante. En cuanto a la 45, en que se bromea acerca de los pasados verdores y actual apocamiento amoroso del demonio, «ese personage del qual todavía no tenemos noticias bien seguras, después de tanto como se ha dicho en las Leyendas áureas de los Santos y en los Autos sacramentales de Calderón», parece probable que el nuevo editor - aunque a primera vista sea paradójico - se negó a reimprimir un texto que «desprestigiaba» demasiado al ángel malo, pero también, por cuanto negaba implícitamente su existencia, resultaba ofensivo al dogma católico y no estaba en línea con la propaganda patriótica que proclamaba la naturaleza diabólica del Emperador. En la nota 10 tampoco se le había escapado al gaditano una frasecita entre paréntesis que manifestaba la misma duda de don Leandro acerca del Príncipe de las Tinieblas; e igual suerte le cupo. No tenía más garantías de ser admitida en Cádiz la alusión a la supresión de los conventos por Napoleón («[...] ya no hay padres que la administren [...]»), ni la formulación sar-

55 Solis, p. 298.

56 E. Sarrablo Aguareles, La vida en Madrid durante la ocupación francesa, Zaragoza, Institución Fernando el Católico, 1964, p. 289.

57 Cotarelo y Mori, Isidoro Máiquez, Madrid, Imprenta J. Perales, 1902, pp. 292-293, n. 1.

58 Solis, p. 309.

59 Mesonero Romanos, Memorias, Madrid, Tebas, 1975, p. 67. 
cástica de la esperanza en una vuelta a la situación anterior. Al final de la nota 13, que no es más que un largo extracto del Diccionario filosófico de Voltaire, se tuvo por conveniente omitir la mención de la obra y del autor - a los que Moratín podía en cambio referirse sin temor en 1811 -, pues ocupaba el escritor francés un lugar eminente en el Indice expurgatorio desde decenios atrás; por lo tanto, la cita, que tampoco venía entrecomillada en la edición de don Leandro, pierde gráficamente su calidad de tal en la de Cádiz; en otra nota, la 53, queda convertido Voltaire en «un Filósofo», prudente eufemismo si tenemos presente el a la sazón bajo crédito de la «falsa filosofía», origen de todos los males en opinión de los serviles. Este mismo contexto es lo que permite explicar el corrimiento de la primitiva «intolerancia» inquisitorial hacia el «despotismo» en el Prólogo del editor gaditano: la voz «tolerancia» y otras semánticamente afines eran poco gratas a aquellos españoles para quienes la lucha contra el ocupante era también una guerra de religión; en el Despertador christiano-político del Padre Simón López ${ }^{60}$, más conocido por su Pantoja, se lee por ejemplo el diálogo siguiente:

P[regunta] - ¿De qué armas se vale el imperio francés para amplificar sus estados $[. .$.$] ?$

R[espuesta] - De la tolerancia religiosa; ésta es ley fundamental; con esto se lisonjean sofocar la única verdadera Religión, que les incomoda, que es la católica romana.

Esto lo escribía cuatro años antes en Murcia un presbítero del Oratorio de San Felipe Neri a quien sus paisanos habían de elegir para que los representase en las Cortes de Cádiz ${ }^{61}$. Además, al sustituir la «intolerancia» por el «despotismo», el editor andaluz mataba dos pájaros de un tiro, pues renunciaba a una voz entonces sospechosa para los ultramontanos quisquillosos, en benefi-

61 «Se ha visto proclamar ya la tolerancia religiosa, y estos males...» (Benito Ramón Hermida, diputado por Galicia, en Actas..., p. 1.149). 
cio de otra no menos expresiva, pero de connotación ya más política que religiosa, patriótica, mejor dicho; una voz, pues, más apropiada para las circunstancias, y por ende de más general aceptación.

Donde las podas o enmiendas son más radicales es naturalmente en aquellos pocos pasajes en que don Leandro manifestaba implícita o explícitamente su adhesión al régimen del Intruso, pues en lo que más se diferenciaban afrancesados y «doceañistas» era en lo político. La primera frase del Prólogo del editor de 1811 , en que desea el autor que se estudien las causas del atraso de España a principios del XIX tan pronto como se recobre la «tranquilidad que turbaron las pasiones y la ignorancia», equivale ya a una toma de postura política por su misma formulación, por cuanto las «pasiones» y la «ignorancia», a pesar de la aparente abstracción y generalidad de las voces, apuntan al partido opuesto a la «razón»e «ilustración», al menos según los josefinos, es decir, a la España insurrecta, en poder, según los mismos, de la «plebe» embrutecida y amotinada con la bendición del clero retrógrado. Las dos características de los presuntos factores de disturbios aparecen con mayor claridad en otro texto moratiniano levemente anterior ${ }^{62}$, en el que se censura a los oradores cristianos que aseguraban desde el púlpito que «una mudanza de dinastía era un conflicto de la religión», al predicador que "aprovechándose de la estupidez del vulgo la adula y la excita, pone en movimiento las inclinaciones feroces que es de su cargo reprimir [...] y sacrifica a la destemplanza de sus pasiones tantas víctimas cuantos son los infelices a quienes su elocuencia infernal persuade y acalora». "Tantos años de ignorancia y de opresión -añade- no prometían mejores frutos", pero ha llegado el tiempo en que ya no se ha de ver a un «Tribunal de tinieblas» que castigue la censura de errores funestos para la sociedad. Es análogo el enfoque de la situación por el general francés Sebastiani en su carta de 1809 a Jovellanos ${ }^{63}$, pues le aconseja al asturiano

62 Prólogo para una ed. del Fray Gerundio, en Obras Póstumas, III, p. 209 (fecha: 1812).

63 M. Láfuente, Historia General..., 12, p. 389. 
que abandone «un partido que sólo combate por la Inquisición, por mantener las preocupaciones, por el interés de algunos grandes de España...», una España que vio próxima ya su total disolución a consecuencia de «los vicios y desórdenes de su gobierno» y en cuya «regeneración» está trabajando «el héroe que admira el mundo».

El editor gaditano tacha, como era de esperar, tan poco halagüeña alusión a sus compañeros de lucha, afirmando por su parte que quien despojó a España de su tranquilidad fue «la perfidia del más ambicioso de los tiranos Napoleón Bonaparte» y deseando que renazcan las letras «mediante el benéfico influjo que proporcionan las sabias instituciones demarcadas en la Constitución que han establecido, a costa de afanes y fatigas, los representantes de esta gran nación, congregados en Cortes generales y extraordinarias». Tampoco se admite el segundo apartado de la nota 60 y última, prácticamente desconocido en la actualidad, pues ni siquiera el concienzudo Aribau se atrevió a reproducirlo en 1846 en el tomo segundo de la Biblioteca de Autores Españoles ${ }^{64}$ : y es que en él indudablemente se ha propasado Inarco: deseoso de asestar el postrer golpe al odiado tribunal, evoca al «gran Caudillo que al frente de cincuenta mil hombres acabó en Chamartín con las bárbaras leyes que dictó la ignorancia», es decir, con el Santo Oficio, el 4 de diciembre de 1808, pero añade a renglón seguido que «en Uclés, Medellín, Almonacid, Ocaña y Tarragona se refrendó el decreto Imperial», exaltando a través de la abolición de la "Santa» cinco victorias de las fuerzas invasoras conseguidas entre enero de 1809 y junio de $1811^{65}$. Por últi-

64 En la ed. de la B.A.E. se reproducen todas las notas de la de 1811 o de la de principios del trienio liberal, menos el final «napoleónico» de la referida nota 60 , de manera que la decisión de suprimirlo, como hizo antes el gaditano o el mallorquín, debió de tomarla a su vez Aribau con pleno conocimiento de causa.

65 El último párrafo de esta nota postrera es el siguiente:

Si de hoy en adelante hemos de carecer de estos devotos y entretenidos espectáculos, la culpa tiene el gran Caudillo que al frente de cincuenta mil hombres acabó en Chamartín con las bárbaras leyes que dictó la ignorancia, en oprobrio de la humanidad y de la razón. En Uclés, Medellín, Almonacid, Ocaña y Tarragona se refrendó el decreto Imperial; y todo ha sido menester para desterrar de una nación obstinada e ilusa tan absurdas opiniones, tan inicuos tribunales, $\tan$ groseras y feroces costumbres. 
mo, el editor liberal no podía cerrar los ojos a la asociación, simbólica para un afrancesado, de la Inquisición y de las «juntillas» -así se llama despectivamente en el texto de Madrid a las juntas locales o partidas de guerrilleros-, o sea, según queda dicho ya, a la asociación de la «ignorancia» y de la «pasión» propias de la España rebelde. Por estar convencido de que las referidas juntillas no andaban «por esos montes acabando de aniquilar a la infeliz España», según escribe Moratín ${ }^{66}$, prefirió el gaditano ajustar las cuentas a los enemigos de dentro de casa, y particularmente a los portavoces de la ideología reaccionaria, «Filósofos rancios, Censores, Abates diarreas y otros de este jaez que trabajan incesantemente por impedir que se ilustre la noción [sic], para que la infeliz España siga como hasta aquí baxo la opresión y fanatismo más vergonzoso": Fray Francisco de Alvarado, de la orden de Predicadores, alias el «Filósofo Rancio», que comenzó a publicar sus Cartas críticas... en 1812 y ya era conocido en Cádiz en $1811^{67}$; el Censor general, órgano del partido antirreformista y que se había declarado a favor de la Inquisición; y otro periódico titulado Diarrea de las Imprentas, calificado de «furiosamente antirreformista» ${ }^{68}$ por Ramón Solís y redactado, según el mismo, por un fraile; este último folleto, que debía su título a una epidemia, señalaba como primer requisito para curar la enfermedad el respeto al Santo Tribunal de la Inquisición. Y si se tienen en cuenta las acaloradas disputas acerca de la soberanía, de si residía en el rey o en la nación (por lo que «cada particular individuo de ella es soberano; luego el hijo es soberano del padre y los esclavos de sus amos; luego hay un número infinito de soberanos») ${ }^{69}$, no habrá de extrañar el que los hechizos del «soberano» Carlos II evocados por Moratín en la nota 52 lleguen a con-

Nota 35 (de la B.A.E., según apunto en la n. 54).

67 Arremete contra él un tal don Silvestre Canuto Cirilo ahí me las den todas, en el Diario Mercantil de 29 de octubre de aquel año, sin perdonar tampoco a los «Diarreas» (Solís, p. 282).

68 P. 491.

69 El Censor General, n. ${ }^{\circ}$ 8, en Solís, p. 281. 
formarse al artículo tercero de la constitución, aquejando ya al «monarca» en la edición gaditana.

Esa influencia del entorno político y religioso no es la única que se manifiesta en las modificaciones sufridas por las notas moratinianas al acomodarse al gaditano modo; varios pormenores de la vida diaria de Madrid, que Moratín introducía en su texto para hacer más amena y persuasiva su lectura, dejan necesariamente de tener interés para el público de la ciudad andaluza, y el nuevo editor resuelve por lo tanto suprimirlos o adaptarlos: así por ejemplo, en la nota 25 , la referencia a la tienda de vestidos de Castillo, cuyo dueño desaparece a cambio de un simple plural («las tiendas»); según la 57, también en Cádiz se usan hábitos de San Francisco, pero ya no se puntualiza que los venden «los cereros»; en la 27, los «caxones de la plaza» se convierten en «canastos de la pescadería», y la típica «guardilla» en simple «casa»; la 20, que principiaba con una breve frase sarcástica acerca de la eficacia de la invocación a Jesús y Santa María, tampoco podía subsistir, porque en ella se enumeraban unas nueve comedias taquilleras de las que sólo tres se representaron en Cádiz durante el período que estudiamos ${ }^{70}$; en cambio, en la 55 se convierten «los teatros de la Corte» en «el teatro de Cádiz», y las «gradas» madrileñas en «tablillas», que efectivamente eran unas localidades propias del teatro antiguo de la calle Novena ${ }^{71}$; del tramoyista Baus ya no se podía hablar, pero la crítica generalizadora de Moratín a los actores de la Villa («los cómicos quedarán ricos, y por consiguiente querrá Dios que no vuelvan a representar en su vida») se atenúa notablemente en la edición gaditana: «... querrá

70 Solís, pp. 395 y ss.

71 Solís, p. 403; por estar demasiado expuesto al fuego de las baterías enemigas, se edificó en el campo del Balón un teatro nuevo, el de San Fernando, cuya inauguración fue el 26 de agosto de 1812. Pero de la lectura de distintas obras dedicadas a aquel período no he conseguido deducir que ese acontecimiento supusiese el cese de la actividad del teatro antiguo, de manera que no se puede considerar dicha fecha, al menos por ahora, como terminus ad quem para la nueva redacción, por el anónimo gaditano, de las notas del Auto (véanse E. Quintana Martínez, Teatro de las Cortes, Cádiz, 1910, pp. 50 y ss.; Solís, o.c., pp. 381 y 403; A. Alcalá Galiano, Recuerdos de un anciano, B.A.E., LXXXIII, p. 89 b). 
Dios que los malos no vuelvan...», porque si no faltaban los comicastros, según la prensa de aquellos años, también había representantes muy buenos refugiados allí, como el gran Mariano Querol, o Coleta Paz, la «Coletita» del diario íntimo de Moratín de antes de la guerra, y por otra parte las Cortes acababan de solventar el concepto de indignidad profesional que pesaba sobre el oficio de cómico, por lo que éstos colocaron una lápida conmemorativa en la puerta del teatro el día 25 de junio de $1812^{72}$.

Por último, no estando ya los tiempos para «discursos académicos», como se explica en la advertencia final de 1812 , de nada servía entonces, pues se trataba de alcanzar al mayor número posible de lectores, la nota 17 , reducida a una cita latina, es decir, a un mero adorno. Otra cita, de la Biblia (Levítico, XX, 15-16), mejor dicho, de la Vulgata, relativa al pecado de «bestialidad», falta en el texto de la nota; se dejó subsistir otra en la 49 (Reyes, I, IV , 13), tal vez por ser más inocua, pero el caso es que, tratándose sobre todo de citas, no siembre se dejan percibir claramente los criterios en que se fundó el editor gaditano para conservar unas y censurar otras, o para dejar, por ejemplo, «sub Jove frigido» en la nota 27 y quitar «tacto pectore» en la siguiente; ¿se omitió la frase proverbial «vous êtes orfèvre, Mr. Josse», sacada de $L$ 'amour médecin de Molière, por estar formulada en el idioma de los que bombardeaban Cádiz, o por ofensiva a los domini$\cos$ ?

La edición que realizó la Imprenta Real (la legítima, naturalmente, no la josefina) de Mallorca el año siguiente, $1813^{73}$, se funda como es lógico en criterios parecidos a los que supone la anterior, aunque no coincide totalmente - me refiero al texto de las notas moratinianas - con ella. El editor, que sustituyó el prólogo de don Leandro por otro más breve de propia cosecha en

72 Solís, p. 406.

73 Agradezco a la Houghton Library de la Universidad de Harvard el haberme mandado fotocopia del documento. 
vez de modificarlo como hiciera el gaditano ${ }^{74}$, conocía las dos impresiones de 1811 y 1812 , por lo que, partiendo del texto, más correcto, de las notas de la primera, rectificó las erratas contenidas en el de Cádiz, algunas de las cuales dejamos apuntadas en su lugar.

Tampoco parece que conozca el mallorquín la verdadera identidad del «Bachiller Ginés de Posadilla», cuyo nombre falta en la portada con toda la parte del título gramaticalmente incorrecta de 1812, a cambio de lo cual se menciona en el pie de imprenta que se trata de una nueva edición. Según el prologuista, las de 1811 eran unas notas "marcadas con el tributo que exige de sus esclavos el orgullo francés, y de las cuales se tomaron en la edición de Cádiz, hecha en 1812, solamente aquellas que manifiestan el ridículo de este escrito cómicamente, y que por lo mismo son capaces de dulcificar con sus sales lo que hay en él de repugnante y horrible»; extraña frase que no sólo reproduce, como si fueran del editor gaditano, los términos empleados por Moratín en su prólogo de 1811 , sino que queda en cierto modo refutada por la advertencia final de la edición de 1812 , en la que, se nos dice, «no se ha tratado [...] de ridiculizar [...] los abusos [...] del más monstruoso de los tribunales», nueva prueba, conviene advertirlo, de la prisa con que se realizó la edición de la imprenta Tormentaria. Sea comoquiera, esta «4. ${ }^{a}$ edición [...] va todavía menos adornada que la de Cádiz», en primer lugar porque se ha considerado "agena de este asunto la mucha erudición». Se trataba en efecto ante todo, ya "derribado el sanguinario coloso", de «hacer vulgares los datos en que se fundó la determinación, la acertada determinación de las Cortes, y hacer fijar al público la vista sobre un principio casi puesto en olvido, a saber, que unos cuantos hombres ilustrados valen muy poco a una nación sujeta a un gobierno sin responsabilidad que descargue sobre quien se le antoje la mano misma que estendió la ley»; estas palabras muestran que la nueva edición del texto del $A$ uto tenía la misma finalidad que la publicación del Manifiesto en que las Cortes expusie-

74 El final lo constituye sin embargo una cita del texto del «editor de Madrid». 
ron los motivos del decreto de abolición expedido el 22 de febrero después de aprobado el 22 de enero por 90 votos contra $60^{75}$. En marzo, también el 22, envió el ministro de Gracia y Justicia a los obispos una circular en la que les mandaba «imprimir y circular a todos los pueblos de su Diócesis» ambos documentos ${ }^{76}$, por lo que debió de realizarse la edición mallorquina en la primavera de 1813.

Menos «erudición», se ha dicho; a consecuencia de ello se suprime desde el principio el epígrafe procedente del libro III de las Odas de Horacio: «Hoc fonte derivata clades / in patriam populumque fluxit»; de las notas que subsistían en la edición anterior salta la segunda ${ }^{77}$, que pertenece -exceptuando la tonalidad irónica- al género poco grato al mallorquín, pues se refiere a una alabanza dirigida por Esteban Manuel de Villegas al impresor Juan de Mongastón, no sólo editor del Auto sino también de las Eróticas; no se consideró en 1813 que venían «como de perlas cuatro versos del buen Camoens» para adornar el relato del canibalismo de los brujos, y desaparecieron también con la nota 58. A la $3 .^{\text {a }}$, mero alfilerazo sin mucho alcance, le cupo la misma suerte que a las anteriores, pero estas supresiones quedan contrapesadas por otras tantas reincorporaciones, mejor dicho conservaciones ${ }^{78}$, de manera que el número total viene a ser el mismo que en 1812 , esto es, 55 notas ${ }^{79}$, de las 60 iniciales con que

75 Martí Gilabert, pp. 257 y 258 en particular. Algunas expresiones ( Trabajamos en un tiempo...»; «... no tenemos que prevenir el juicio de nadie [...] sobre nuestra conducta...» -mío el subrayado-), el ser obra de la Imprenta Real la nueva edición, son elementos todos que parecen conferirle a ésta cierto carácter semioficial.

El que las Cortes mandasen hacer un tomo especial con los discursos de los que intervinieron en el debate sobre la Inquisición demuestra por otra parte la importancia excepcional del decreto que lo remató.

76 Martí Gilabert, p. 254.

77 Recordemos que seguimos la numeración de la B.A.E.

78 Con relación al texto de 1811 .

79 Para facilitar la impresión se colocaron todas, numeradas de la 1 a la 55, al final de la obra. 
don Leandro comentó el texto del Auto. Las que el mallorquín resolvió conservar son la 7, poco compasiva con la persona de los inquisidores; la 17, lo cual contradice, adviértase, el propósito declarado de evitar los comentarios meramente eruditos, a no ser que se trate de un simple descuido; y por último la 19, en que se comenta con sarcasmo el culto a la Virgen, si bien no se llega a transcribir por completo la frase de Moratín, quien, como hemos visto, calificaba a María de «tanto numen», pues «llamaban así los Gentiles a qualquiera de los Dioses fabulosos que adoraban», según puntualiza el primer diccionario de la Academia Española.

Además, con el indudable fin de evitar prolijidades, el mallorquín abandonó la forma dialogal de la nota 35 en que disputan varios lectores de la relación del auto acerca de si conviene o no imprimirla íntegra o desistir de publicarla, de manera que queda escamoteado el problema entonces candente de la expurgación de los textos. El editor de 1813 no alude a la posible expurgación, por lo que la determinación que manifiesta en su nota, reducida a compendio, parece más rotunda que la de don Leandro; pero la desmiente el pasaje del $A u t o$ a que se refiere, totalmente idéntico al publicado en 1811 y 1812 , es decir, con las supresiones que ya he mencionado más arriba. En cambio, sí juzga necesario puntualizar con Moratín que de la descripción de la misa negra no ha de resultar ningún perjuicio para «el más digno sacrificio que han ofrecido los hombres a la divinidad», y añade, ya de propia cosecha, que «de ser posible, hubieran tenido buen cuidado de no tramarla [aquella «farsa»] los que siendo, accidentalmente, inquisidores, no podían desprenderse del sublime carácter de Sacerdotes del Altísimo». No ofrecía mucho interés el párrafo relativo al caso del alcalde Ronquillo, ánima en pena, pues se limitaba Moratín, al final de la nota 57, a decir que por no ser prolijo dejaba de contarlo. Y desapareció, quedando por lo mismo suprimida la referencia a una página anterior, causa de equivocación para el editor de Cádiz.

Tampoco se volvió a imprimir en 1813 la nota 20, ya desechada por el gaditano, pues consistía esencialmente en una lista de 
comedias representadas en Madrid en los años anteriores, aunque cinco de ellas al menos se pusieron en cartel en Palma durante los años 1812-1813 ${ }^{80}$; ya no se expresa el lugar ni la fecha de la representación de la estupenda tragedia de magia, parto del menguado ingenio del «sobrinito»; se omite asimismo la mención de la «grada» según la versión madrileña, o de las «tablillas» según la de Cádiz, que se destinaban a las «señoras mujeres» para presenciar la función; del «tramoyista» no se trata, ni de los «malos» cómicos, seguramente por sentir el nuevo editor menos interés que su antecesor y que el comediógrafo Moratín por esa clase de pormenores al fin y al cabo ajenos a su propósito ${ }^{81}$, porque del estudio de Manuel Larraz sobre el arte dramático en Palma por aquellos años se colige por el contrario que las preferencias de los mallorquines, las preocupaciones de los aficionados del recién reformado teatro, eran muy parecidas a las de los madrileños ${ }^{82}$. Por último, huelga recordar que también dejó de imprimirse en 1813, y no por ocioso, el final de la nota última, ya borrado desde el año anterior, por ofensivo a los ejércitos entonces derrotados por el invasor.

Esta tendencia a la retirada o al arreglo de lo tenido por superfluo se advierte asimismo en la nota 10 , en que se suprime el último párrafo con la larga cita del Tasso, aunque también debió de influir en la resolución del editor el excesivo desenfado con que trata Moratín al demonio, se quiera o no se quiera persona de alta categoría. La cita bíblica de la nota 41 , relativa al pecado de bestialidad, ya borrada en 1812, tampoco la saca a relucir el editor de Mallorca, y en este caso también cabe cierta ambigüedad en sus móviles. Es que si quedaba entonces abolido el tribunal de la Inquisición en la España insurrecta como «incompatible

80 Véase Manuel Larraz, «Le théâtre à Palma de Majorque pendant la guerre d'Indépendance: 1811-1814», Mélanges de la Casa de Velázquez, 1974, pp. 345 y ss. La lista de comedias que figura en el apéndice no es completa, según el mismo hispanista.

81 Por la misma razón que la expuesta en mi $n .79$ se ponen seguidos casi todos los nombres de los actores de la «tragedia» y sus correspondientes papeles en la n. 51 (55 en B.A.E.), en vez de venir aparte como en las ediciones anteriores.

82 Véase n. 80 . 
con la Constitución» por el artículo segundo del memorable decreto, el artículo primero estipulaba para tranquilizar «las conciencias más escrupulosas», según escribe Lafuente, que la religión católica había de estar protegida por la ley, y se trasladaba a los obispos la facultad de prohibir los escritos que fuesen contrarios a ella; por otra parte, en aquella "guerra teológica» ${ }^{83}$ importaba tener presente la fuerza del arma religiosa contra el invasor. De manera que tampoco en 1813 se pudo atribuir a su legítimo autor la larga cita procedente del Dictionnaire philosophique del «impío» Voltaire, que constituía en 1811 la nota 13, y se siguió aludiendo a un anónimo «filósofo» en la 53 en vez de nombrarle. No sabemos si fue verdaderamente intencionada la conservación, en la nota 10 , de la breve frase escéptica relativa a la existencia del demonio, pues no se atrevió el mallorquín, siguiendo en esto a su antecesor, a imprimir la 45 por atentatoria, digámoslo así, a la dignidad de aquel «maldito de Dios»: era en efecto preferible no atizar el fuego proporcionando un argumento más a los que seguían asimilando abiertamente, incluso en las Cortes, la oposición al Santo Oficio o el anticlericalismo a la impiedad.

Esas precauciones, tomadas a veces sin el suficiente detenimiento, y por lo mismo no exentas de algún formalismo, pueden llevar a ciertas contradicciones: en la larga nota 56, en que Moratín evocaba una oración para las lombrices que «declamaban» los monjes bernardos, «de feliz memoria», esto es, antes de la supresión de los conventos por decreto de Napoleón, se ha convertido naturalmente en presente de indicativo en las dos ediciones de 1812 y 1813 el imperfecto original, pero sin quitar la especie de despedida sarcástica de don Leandro a una orden que ya había dejado de existir, al menos en la parte ocupada de España.

La Inquisición, como es sabido, fue restablecida por real decreto de 21 de julio de 1814, unos meses después del regreso de Fernando VII, hasta el 9 de marzo de 1820 , en que un nuevo decreto, fundándose en el de 22 de febrero de 1813, la volvió a su-

83 La expresión es de Dufour, o.c. 
primir. Entonces apareció otra vez, coincidiendo con el inicio de un nuevo período de liberalización, el Auto de fe de Logroño de Moratín.

De esta edición madrileña de 1820 por Collado no hay prácticamente nada que decir, pues es en todo conforme a la de $1811^{84}$, llegándose incluso a publicar la totalidad de la última nota, en que se celebran las victorias de Napoleón sobre el ejército de los patriotas. No la llevó a cabo el mismo don Leandro, pues llegó a Barcelona, procedente de Italia, el 10 de octubre ${ }^{85}$ y dos años más tarde encargaría desde Burdeos un ejemplar a su apoderado y amigo García de la Prada. Pero si se publicó entonces íntegro el texto de las notas fue indudablemente porque a consecuencia del alzamiento victorioso de los constitucionales ya no había necesidad de guardar miramientos a los serviles, como ocurrió en Cádiz ocho años antes.

La paginación es idéntica a la de 1811 , y también la composición, aunque ésta presenta a menudo, a partir de la página 73 , unos leves desajustes con relación al modelo inicial, cuyas consecuencias se consigue atajar varias veces. Pero interesa destacar que aquel mismo año en que triunfaron los constitucionales se reeditó por el mismo Collado otra relación, impresa a fines del XVII por Joseph del Olmo ${ }^{86}$, la del Auto general de Fe celebrado en Madrid en 30 de junio de 1680; el ejemplar de la sección de Raros de la Biblioteca Nacional de Madrid está encuadernado con el del Auto de Logroño publicado por el mismo impresor, y no es mera casualidad, pues desde la portada nos enteramos de que se publicó «ilustrado con notas por un Aficionado a esta cla-

84 Como en 1812 se omite puntualizar el núm. de la ed., por lo que también queda gramaticalmente incorrecta la expresión: «ilustrada con notas». Salió el anuncio en la Gaceta de Madrid del 29 de junio 1820 (n. ${ }^{\circ} 100$ ); se vendía el tomito a 6 reales en rústica «en las librerías de Orea, calle de la Montera, y de Sojo, calle de las Carretas». Interesa advertir que poco antes se reimprimió también la Memoria histórica de Llorente (Gaceta de 20 abril).

85. Moratín, Epistolario, Madrid, Castalia, 1973, carta 184, 11 octubre 1820.

86 Miguel del Olmo se le llama en la reedición. 
se de diversiones», a imitación de Moratín; el prólogo no deja lugar a dudas, pues afirma que la tal «función» excede «en tercio y quinto a la que setenta años antes se había dado a los vecinos de Logroño por los inmortales inquisidores de Navarra. ;Oh, quién me diera que este auto que yo publico hubiese sido anotado por el divino Ginés de Posadilla, natural de Yébenes!»; y aclara la nota correspondiente: «El inmortal Don Leandro Fernández de Moratín, gloria y honor del teatro español, y mengua de un injusto gobierno" ${ }^{87}$, palabras las últimas corrientes en aquella épo$\mathrm{ca}$, y que ejemplifican el acercamiento obrado por los años negros entre ex «afrancesados» y liberales ${ }^{88}$, es decir, entre dos familias antes políticamente divergentes de partidarios de las Luces. De aquel auto de 1680, «el auto de los autos, el auto de fe por excelencia, y que ha merecido la aprobación de todos los fanáticos», se trató ya, según vimos, en la sesión de Cortes de 18 de enero de $1813 \mathrm{y}$, merece la pena advertirlo otra vez, después de referirse el orador al de Logroño reimpreso al finalizar el año anterior: en un pasaje del discurso que leyó en su lugar el diputado secretario Florencio Castillo, Ruiz de Padrón resumió y comentó el relato de "José Olmo», entre indignado y sarcástico, añadiendo que antes de la guerra tuvo la oportunidad de leer en la biblioteca de San Isidro de Madrid un trozo del sermón «gerúndico» que se predicó en aquella solemnidad ${ }^{89}$.

Ésa fue, pues, la posteridad de la Relación de 1611, al menos en vida de Moratín, ya que, como es sabido, después de la muerte de Fernando VII y de la supresión definitiva de la Inquisición al año de fallecer el rey, se publicó suelto por última vez el folleto en 1836 por un editor de Barcelona. 1811, 1812 y 1813, 1820: las cuatro reediciones sucesivas del texto áureo con las notas del

P. XII. Se identifica ya al autor en el anuncio de la Gaceta cit. en n. 84 .

88 «Miran algunos - escribe el editor - como un desdoro de la magestad el que las Cortes tomen juramento de fidelidad a los Reyes...» (p. 50).

89 Actas..., II, p. 1.186. Inmortalizó aquel auto el pintor Francisco Rizi en un cuadro conservado en el Museo del Prado. 
autor de La mojigat́a coinciden perfectamente con unos momentos de la historia decimonónica en que vaciló el poder de la monarquía absoluta y de la institución que compartió con el Estado el control ideológico del pensamiento. Lo que fue al principio relación de solemnidades, literatura más o menos edificante y a un tiempo homenaje indirecto a los campeones de la ortodoxia católica, se convierte dos siglos después en pieza de convicción esgrimida contra el símbolo del oscurantismo por los herederos de la Ilustración momentáneamente desavenidos en lo político. Si el texto del auto permaneció íntegro -exceptuando el pasaje escabroso arriba mencionado-, en cambio las notas moratinianas sufrieron algunas vicisitudes que reflejan bastante bien las distintas circunstancias en que se reeditaron hasta el trienio constitucional. Abolida definitivamente la Santa el 15 de julio de 1834, apareció la «quinta edición» por Verdaguer en Barcelona, dos años después, como tardía despedida; el mismo título supone ya un enfoque más distanciado: Arte de brujería y relación del auto de $f e[\ldots]^{90}$; media un cuarto de siglo entre la publicación del texto del Siglo de Oro por Inarco y la del impresor de la ciudad condal; han transcurrido tres lustros desde la de Collado. Que pasen dos más, y se llega al año en que Aribau da cabida al Auto de fe de Logroño entre las obras del escritor clásico Leandro Fernández de Moratín, en el volumen segundo de la no menos clásica Biblioteca de Autores Españoles.

Caro Baroja alude alguna vez a una posible ed. de 1833, que al parecer no ha visto. Yo la desconozco, ni consta en ninguna bibliografía moratiniana. Por otra parte, el único ejemplar actualmente conocido de la ed. de Barcelona 1836, custodiado - valga la palabra - en la Library of Congress de Washington, ha desaparecido y no ha vuelto a aparecer a pesar de los esfuerzos de mi buen amigo John H. R. Polt. 


\section{A P É N D I C E}

\section{PRÓLOGO DEL EDITOR 91}

Cuando cesen los estragos de la guerra y la nación adquiera la tranquilidad que turbaron las pasiones y la ignorancia, restituidas ya las letras a nuevo esplendor, será oportuno estudio de sus más acreditados escritores investigar cuáles hayan sido los orígenes de la general depravación de ideas y costumbres y del atraso en que se ha encontrado nuestra nación a principios del siglo XIX, cotejada con las demás de Europa. Apenas aplicarán su atención a este examen cuando hallarán en el establecimiento del tribunal de la Inquisición y en la ilimitada autoridad que ha ejercido por espacio de tres siglos en la península una de las causas más poderosas de donde por necesidad se han derivado tan funestos males.

Copiosa materia presentarán al historiador erudito y filósofo aquellos siglos bárbaros en que se manifestaron los primeros furores de la persecución religiosa, continuada en lo sucesivo con sujeción a método y formas, y erigida por último en tribunal de intolerancia y error. Él dirá por cuáles méritos supo adquirir la protección y el favor de la Silla Romana, y qué fines se propuso lograr aquélla en sostener un establecimiento tan contrario a la prosperidad de las naciones. Qué pudo inducir a los Reyes de España a permitirle una autoridad que, embruteciendo al pueblo y usurpando la jurisdicción episcopal, amenazaba al trono mismo. Cómo pudieron mirar con indiferencia las ilustres víctimas que sacrificó en el exceso de su frenesí. Cómo no advirtieron que detenía los progresos de la ilustración, propagaba errores absurdos, atropellaba la

91 El de Moratín, que encabeza la ed. del texto del Auto por la Imprenta Real, M., 1811 (véase n.

7). Transcribo el texto según las normas actuales. El prólogo empieza en la p. 3; en el medio de la p. 2 está el siguiente epígrafe:

Hoc fonte derivata clades In patriam populumque fluxit

Horat. lib. III.

Se trata, como es sabido, del libro tercero de las Odas. 
formalidad de las leyes, los derechos más sagrados de los hombres, castigaba delitos que es imposible cometer, y oponía obstáculos invencibles a la gloria, al poder y estabilidad del grande imperio que gobernaban.

Algunos extranjeros se han anticipado a tratar de estas materias; pero siempre que han querido contraer las ideas generales a nuestro carácter particular, nuestras instituciones y costumbres, lo han hecho por lo común con menos acierto que cuando han hablado de los pueblos más ignorados y remotos. Sea ligereza suya, sea culpa nuestra de no haberles podido suministrar los documentos que son necesarios para ello, lo cierto es que abundan de errores los escritos que han publicado sobre este propósito, y que todavía se ignora mucho lo que fuimos, lo que somos ahora, y lo que pudiéramos ser. Pero ¿quién de nosotros había de escribir en tiempo de tinieblas y opresión? ¿Quién había de obstinarse en ilustrar a un Gobierno que condenaba las verdades y los errores, la sabiduría y la superstición, el vicio y la virtud a una misma hoguera?

Es tiempo ya de producir documentos para que otras plumas, sin exageración, sin parcialidad, sin encono, describan el origen, los progresos y el suspirado término de nuestra calamidad; y entre los que pueden darse a la luz pública, tal vez no habrá ninguno que reúna en menos volumen más decididos rasgos de ignorancia, de atrocidad, de torpeza y ridiculez que el presente opúsculo. Por él se verá lo que dos siglos hace creía el vulgo, castigaba el tribunal de la Inquisición, toleraba el Gobierno; viviendo Mariana, los Argensolas, Góngora, el Conde de Villamediana, Quevedo y Cervantes. Cualquiera de estos y otros muchos sabios de conocido ingenio y doctrina, si no hubiesen temido la prisión, la tortura, la afrenta y la muerte, hubieran sido capaces de pintar en todo su horror o de escarnecer con el azote de la sátira tan inicuos procedimientos, que no siempre el silencio es señal segura de complicidad ni de aprobación. Pedro de Valencia, insigne literato de aquella edad, se atrevió con temeraria resolución a dirigir un discurso crítico a don Bernardo de Sandobal y Roxas, manifestándole sus opiniones acerca del abuso escandaloso que hacía la Inquisición de la autoridad que se la confiaba, y de los errores absurdos que promovía cuando pensaba reprimirlos. Existe manuscrita esta obra: ni se imprimió, ni se estimó; y harto fue que su autor no perdió por ella la vida ni la libertad.

Hoy, que es lícito hablar el idioma de la razón y abominar los desaciertos de nuestros padres, sale otra vez al público el Auto de Fe celebrado en Logroño el año de 1610 , exornado con algunas notas en que de propósito ha querido el editor no tomar en consideración lo que hay en él de repugnante y horrible y aprovechar las ocasiones que ofrecen a la pluma las extravagantes ridiculeces de que abunda tal escrito. Si por este medio ha conseguido hacer su lectura menos desagradable, quedará suficientemente premiado el corto mérito que haya podido contraer en solicitar su publicación. 